\title{
Red blood cell "aggregability"
}

\author{
Oguz K. Baskurt ${ }^{\mathrm{a}, *}$ and Herbert J. Meiselman ${ }^{\mathrm{b}}$ \\ ${ }^{a}$ Department of Physiology, Akdeniz University, Antalya, Turkey \\ ${ }^{\mathrm{b}}$ Department of Physiology and Biophysics, Keck School of Medicine, Los Angeles, CA, USA
}

It is well understood that the extent of red blood cell (RBC) aggregation is determined by both plasmatic and cellular factors [10]. It is also clear that alterations of plasmatic and cellular factors may be related to separate disease processes [1]. For example, plasma composition may change (e.g., fibrinogen concentration increase) due to an acute phase response, thereby altering RBC aggregation. Alternatively, RBC aggregation may be altered regardless of plasma composition due to modified cellular properties in certain pathophysiological processes (e.g., diabetes, ischemia/reperfusion injury) [5,9]. Alterations of RBC properties that modify their intrinsic propensity to aggregate can be evaluated by measuring aggregation in standardized suspending media (e.g., isotonic 3\% dextran 70 or $0.5 \%$ dextran 500 solutions). The use of standard media thus eliminates any plasmatic effects and solely reflects cell properties. These measurements in standardized suspending media can then be used to compare different RBC populations: greater aggregation indicates an enhanced tendency of the cells to form aggregates, while lesser aggregation indicates a decreased tendency. It has been suggested that the results of such comparisons reflect RBC "aggregability" [3] and hence intrinsic cellular characteristics such as surface properties (e.g., charge density, glycocalyx structure), membrane mechanical properties and cell shape.

The term "aggregability" is frequently used as being the same as "aggregation" (e.g., $[4,6,7]$ and others), but "aggregation" should mean the extent of RBC aggregation for a given suspension and under defined conditions. Aggregation can be quantitated using various methods and expressed as dimensionless parameters or as parameters reflecting the size of aggregates (e.g., number cells per aggregate), the dynamic behavior reflecting the rate of aggregate formation (i.e., aggregation half-time or aggregation time constants), and the strength of aggregation (e.g., minimum shear to disperse aggregates) [8]. However, RBC "aggregability" can only be assessed if aggregation is measured in a standard aggregating medium and the results compared to another RBC population (e.g., controls) in the same medium [2]. Measurements made in native plasma should not be termed "aggregability".

Differentiating between plasmatic and cellular factors leading to altered RBC aggregation may be important from a physiological and clinical point of view. It has recently been reported that the mechanism responsible for alteration of RBC aggregation is an important determinant of the resulting hemodynamic and vascular effects [11].

\footnotetext{
${ }^{*}$ Corresponding author. E-mail: baskurt@akdeniz.edu.tr.
} 


\section{References}

[1] O.K. Baskurt, Mechanisms of blood rheology alterations, in: Handbook of Hemorheology and Hemodynamics, O.K. Baskurt, M.R. Hardeman, M.W. Rampling and H.J. Meiselman, eds, IOS Press, Amsterdam, The Netherlands, 2007, pp. 170-190.

[2] O.K. Baskurt, M. Bor-Kucukatay, O. Yalcin, H.J. Meiselman and J.K. Armstrong, Standard aggregating media to test the "aggregability" of rat red blood cells, Clin. Hemorheol. Microcirc. 22 (2000), 161-166.

[3] O.K. Baskurt, M. Boynard, G.R. Cokelet, P. Connes, B.M. Cooke, S. Forconi, F. Liao, M.R. Hardeman, F. Jung, H.J. Meiselman, G.B. Nash, N. Nemeth, B. Neu, B. Sandhagen, S. Shin, G.B. Thurston and J.L. Wautier, New guidelines for hemorheological laboratory techniques, Clin. Hemorheol. Microcirc. 42 (2009), 75-97.

[4] M. Blaha, E. Rencova, V. Blaha, R. Maly, M. Blazek, J. Studnicka, C. Andrys, I. Fatorova, S. Filip, M. Kasparova, R. Prochazkova, J. Maly, R. Zimova and H. Langrova, The importance of rheological parameters in the therapy of microcirculatory disorders, Clin. Hemorheol. Microcirc. 42 (2009), 37-46.

[5] B. Chong-Martinez, T.A. Buchanan, R.B. Wenby and H.J. Meiselman, Decreased red blood cell aggregation subsequent to improved glycaemic control in type 2 diabetes mellitus, Diabet. Med. 20 (2003), 301-306.

[6] M. Chwala, A. Spannbauer, A. Teleglow, A. Cencora, A. Marchewka, M.R. Hardeman and Z. Dabrowski, Red blood cell rheology in patients with chronic venous disease (CVD), Clin. Hemorheol. Microcirc. 41 (2009), 189-195.

[7] M. Fornal, R.A. Korbut, J. Krolczyk and T. Grodzicki, Left ventricular geometry and rheological properties of erythrocytes in patients at cardiovascular disease risk, Clin. Hemorheol. Microcirc. 43 (2009), 201-206.

[8] M.R. Hardeman, P.T. Goedhart and S. Shin, Methods in hemorheology, in: Handbook Hemorheology and Hemodynamics, O.K. Baskurt, M.R. Hardeman, M.W. Rampling and H.J. Meiselman, eds, IOS Press, Amsterdam, The Netherlands, 2007, pp. 242-266.

[9] E. Kayar, F. Mat, H.J. Meiselman and O.K. Baskurt, Red blood cell rheological alterations in a rat model of ischemiareperfusion injury, Biorheology 38 (2001), 405-414.

[10] M.W. Rampling, H.J. Meiselman, B. Neu and O.K. Baskurt, Influence of cell-specific factors on red blood cell aggregation, Biorheology 41 (2004), 91-112.

[11] O. Yalcin, P. Ulker, U. Yavuzer, H.J. Meiselman and O.K. Baskurt, Nitric oxide generation of endothelial cells exposed to shear stress in glass tubes perfused with red blood cell suspensions: role of aggregation, Am. J. Physiol. Heart Circ. Physiol. 294 (2008), H2098-H2105. 